\title{
Population Genetics of Plasmodium vivax in Four High Malaria Endemic Areas in Thailand
}

\author{
Kanungnit Congpuong ${ }^{1, *}$, Ratawan Ubalee ${ }^{2}$ \\ ${ }^{1}$ Department of Medical Technology, Faculty of Science and Technology, Bansomdejchaopraya Rajabhat University, Bangkok 10600, Thailand; \\ ${ }^{2}$ Department of Entomology, Armed Forces Research Institute of Medical Sciences, Bangkok 10400, Thailand
}

\begin{abstract}
Recent trends of malaria in Thailand illustrate an increasing proportion of Plasmodium vivax, indicating the importance of $P$. vivax as a major causative agent of malaria. $P$. vivax malaria is usually considered a benign disease so the knowledge of this parasite has been limited, especially the genetic diversity and genetic structure of isolates from different endemic areas. The aim of this study was to examine the population genetics and structure of $P$. vivax isolates from 4 provinces with different malaria endemic settings in Thailand using 6 microsatellite markers. Total 234 blood samples from $P$. vivax mono-infected patients were collected. Strong genetic diversity was observed across all study sites; the expected heterozygosity values ranged from 0.5871 to 0.9033 . Genetic variability in this study divided $P$. vivax population into 3 clusters; first was $P$. vivax isolates from Mae Hong Son and Kanchanaburi Provinces located on the western part of Thailand; second, Yala isolates from the south; and third, Chanthaburi isolates from the east. $P$. vivax isolates from patients having parasite clearance time (PCT) longer than $24 \mathrm{hr}$ after the first dose of chloroquine treatment had higher diversity when compared with those having PCT within $24 \mathrm{hr}$. This study revealed a clear evidence of different population structure of $P$. vivax from different malaria endemic areas of Thailand. The findings provide beneficial information to malaria control programme as it is a useful tool to track the source of infections and current malaria control efforts.
\end{abstract}

Key words: Plasmodium vivax, population genetics, microsatellite marker, Thailand

\section{INTRODUCTION}

Malaria transmission in Thailand is seasonal with sporadic epidemics. The large-scale implementation of control interventions, such as insecticide-treated bed nets, indoor residual spraying, and prompt, free-of-charge diagnosis and treatment has achieved a marked reduction in malaria incidence from 49,521 cases in 2011 to 24,364 in 2015 [1]. The recent annual parasite incidence (API) in 2015 was 0.37 per 1,000 populations. Despite considerable reduction of the total malaria cases, Plasmodium vivax is still prevailed in many parts of the country. The proportion of $P$. vivax to P. falciparum cases increased from $18.9 \%$ in 2011 to $63.2 \%$ in 2015 [1]. Thus, the importance of $P$. vivax species should be increasingly recognized. In contrast to $P$. falciparum, transmission of $P$. vivax is more difficult to interrupt because of its dormant liver forms

\footnotetext{
- Received 7 May 2017, revised 2 July 2017, accepted 2 August 2017.

*Corresponding author (k.congpuong@gmail.com)

(C) 2017, Korean Society for Parasitology and Tropical Medicine

This is an Open Access article distributed under the terms of the Creative Commons

Attribution Non-Commercial License (http://creativecommons.org/licenses/by-nc/4.0)

which permits unrestricted non-commercial use, distribution, and reproduction in any

medium, provided the original work is properly cited.
}

that relapse after clearance of the primary infection, gametocyte production before the occurrence of symptoms, and asymptomatic infections that remain undetected and thus untreated. Most of malaria researches in Thailand based on $P$. falciparum that causes severe and complicated malaria provide useful knowledge on various drug efficacy, drug resistance, molecular markers of drug resistance, and population genetics of parasites from different transmission areas of Thailand. However, $P$. vivax malaria is usually considered as a benign disease, and the knowledge of this parasite has been limited, especially the knowledge on genetic variations of isolates from different endemic areas of Thailand.

Chloroquine followed by 14-day primaquine is the current treatment regimen for $P$. vivax infection in Thailand; its efficacy is still high. However, monitoring of chloroquine drug efficacy during the year 2009-2010 in 4 different high transmission areas, i.e., Mae Hong Son (MH), Yala (YL), Kanchanaburi (KN), and Chanthaburi (CB) Provinces indicated different drug responses as shown by different parasite clearance time (PCT, time taken for parasitemia to become undetectable by microscopy) [2]. In that study, 1 of the 5 patients with reappearance of the parasite within 28-days follow-up had the level of chlo- 
roquine/desethychloroquine above the minimum effective concentration implied to $P$. vivax resistance in one of the sentinel site (KN). The difference may be caused by the genetic difference of $P$. vivax parasites from different geographic origins as illustrated in $P$. falciparum malaria in Thailand $[3,4]$. Understanding parasite genetic difference and its population structure are useful to elucidate the spatial distribution of parasite populations and to predict outbreaks and spread of drug-resistant parasites [5]. Thus, we carried out this study aiming to examine the population genetics and structure of $P$. vivax isolates from 4 provinces with different malaria endemic settings in Thailand.

\section{MATERIALS AND METHODS}

\section{Samples and study sites}

Assuming a 10\% treatment failure rate and a required precision of $10 \%$ around a confidence level of $95 \%$, the minimum sample size was calculated at 50 patients for each site. Total 234 blood samples with $P$. vivax mono-infections were collected in 4 high malaria transmission areas (Fig. 1), i.e., Mae

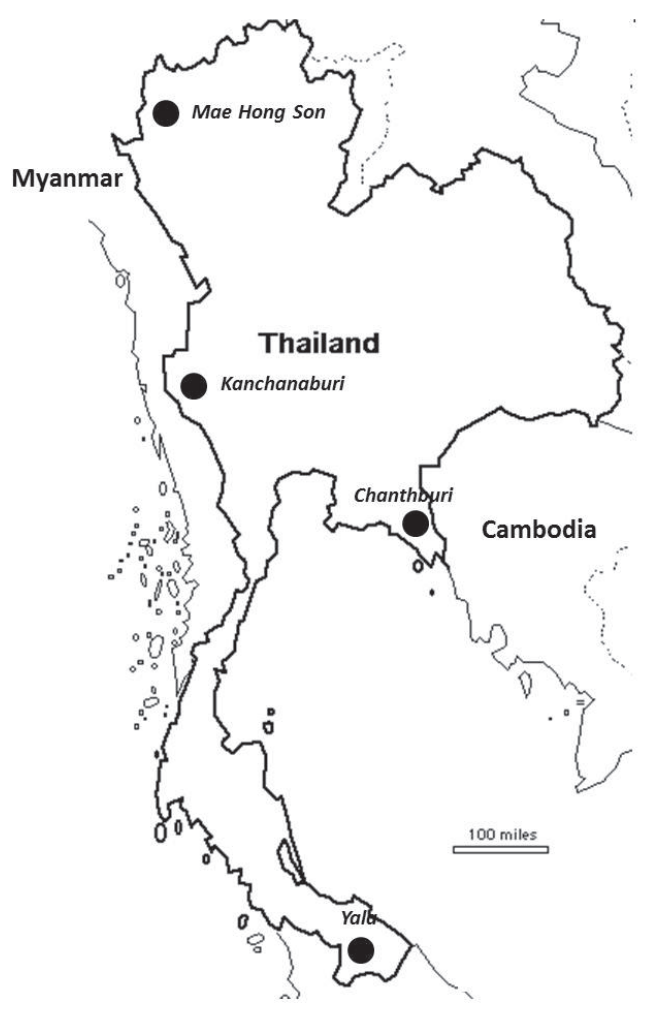

Fig. 1. Map of Thailand showing origins of parasite isolates in this study.
Hong Son (56 samples), Kanchanaburi (68), Yala (55), and Chanthaburi (55). Of these, 212 blood samples were obtained from a previous efficacy study during the year 2009-2010 aiming to assess the efficacy of chloroquine and primaquine for the treatment of P. vivax mono-infection [2], i.e., Mae Hong Son (56 samples), Kanchanaburi (48), Yala (53), and Chanthaburi (55). In addition, 20 samples from Kanchanaburi and 2 from Yala were included in this study. The additional samples were collected during the same period but were excluded from the previous efficacy study because of incomplete following-up of patients. The blood samples obtained from these patients before treatment were genotyped in this study. The study protocol was approved by the ethical committee for research in human subjects, Department of Diseases Control, Ministry of Public Health, Thailand.

\section{Sample collection}

Blood samples were collected from P. vivax malaria patients. Inclusion criteria were uncomplicated $P$. vivax mono-infection confirmed by thick and thin blood films microscopy; parasitemia between 250 and 100,000 parasites/ $\mu$ l of blood; age $>6$ months; axillary temperature $>37.5^{\circ} \mathrm{C}$ or a history of fever in the past $24 \mathrm{hr}$; informed consent from patient or parent/ guardian (in the case of children). Blood from finger prick was collected at day 0 (before treatment) for diagnosis by light microscopy, and 2 blood spots were collected on Whatman 3 $\mathrm{mm}$ filter paper, dried at room temperature, and kept in a plastic bag with a desiccator for microsatellite genotyping.

\section{Light microscopy diagnosis}

Giemsa's stain thick and thin blood films were examined for malaria parasites. Positive P. vivax slides was estimated for parasite density by dividing the number of asexual parasites for 200 white blood cells (WBCs) counted and expressed as the number of asexual parasites per ml blood, assuming 8,000 $\mathrm{WBC} / \mu \mathrm{l}$. All blood slides were double-read by 2 technicians and in case of disagreement slides were read by a third senior technician. A slide was declared negative if no parasites were found after counting 1,000 WBCs.

\section{Genotyping}

DNA was extracted from blood spots on filter paper with the QIAamp DNA mini kit (Qiagen, Hilden, Germany) following the manufacturer's instructions and stored at $-20^{\circ} \mathrm{C}$ until further analysis. Six P. vivax microsatellite markers, i.e., 
PV3.502, PV3.27, MS1, MS5, MS6, and MS16 were used for the genotypic characterization of the field isolates (Table 1). These markers were confirmed by many studies regarding the appropriateness for use in genetic diversity study of $P$. vivax [710]. PV3.502, MS1, MS5, and MS6 were appropriate makers for genetic diversity study, while PV3.27 and MS16 were appropriate for studying multiplicity of the infection [11].

Microsatellite markers were amplified by nested PCR protocol using forward and reverse primers and fluorescence probes as shown in Table 1. PCR amplification was carried out in a total volume of $20 \mu \mathrm{l}$, containing $2 \mu \mathrm{l}$ of DNA solution, 0.25 $\mu \mathrm{M}$ of each primer, $2.5 \mu \mathrm{M}$ of $\mathrm{MgCl}_{2}, 0.5 \mathrm{mM}$ of each dNTP, $1 \mathrm{U}$ of Taq Polymerase (Invitrogen, Carlsbad, California, USA), and PCR buffer. The reaction was performed in a Thermal cycler, VERITI ${ }^{\circledR}$ 96-well Thermal Cycler (Applied Biosystems, Foster City, California, USA) with the following protocol; $1 \mathrm{~min}$ at $95^{\circ} \mathrm{C} ; 40$ cycles of $15 \mathrm{sec}$ at $95^{\circ} \mathrm{C}, 30 \mathrm{sec}$ at $61^{\circ} \mathrm{C}$ and $45 \mathrm{sec}$ at $72^{\circ} \mathrm{C}$, and a final 5-min extension step at $72^{\circ} \mathrm{C}$. The negative control was run by replacing template DNA with $\mathrm{ddH}_{2} \mathrm{O}$ to test for the possibility of contamination. Fluorescence labeled PCR products were analyzed by the Applied Biosystems Genetic Analyzer, i.e., ABI PRISM 3730XL DNA Analyzer (Applied Biosystems) and scored using GeneMapper ${ }^{\circledR}$ v4.0 analysis (Applied Biosystems).

For each locus in each individual isolate, the predominant allele (where multiple alleles were detected) or the single allele was included into the analysis. The predominant allele is defined as the highest peak in electropherogram. Minor peaks taller than $1 / 3$ the height of the predominant allele for each locus were considered to represent multiple alleles per locus. Samples were defined as polyclonal if at least 1 locus presented more than 1 allele. Descriptive statistics were performed using IBM SPSS Statistics for Windows, version 20 (SPSS, Chicago, Illinois, USA).

\section{Genetic diversity analysis}

Genetic diversity for each microsatellite locus in each population was assessed by calculating the number of alleles per locus $\left(\mathrm{N}_{\mathrm{A}}\right)$, the expected heterozygosity $\left(H_{\mathrm{E}}\right)$ per locus and per study site, and haplotypes from haploid data using the Excel plugin software GenAlEx v.6.5 [12]. Haplotypes that appear only once in the population were defined as unique haplotypes. The $H_{\mathrm{E}}$ represents the probability of finding a different allele for a given locus in any pair of samples randomly drawn from the same population. It was calculated using the formula, $H_{\mathrm{E}}=\left[\frac{\mathrm{n}}{\mathrm{n}-1}\right]\left(1-\Sigma P_{i}^{2}\right)$, where ' $\mathrm{n}$ ' is the number of isolates analyzed and ' $P_{\mathrm{i}}$ ' is the frequency of each different allele at a locus. The potential range is from $H_{\mathrm{E}}=0$ (no allele diversity) to $H_{\mathrm{E}}=1$ (all sampled alleles are different). The present study also compared genetic diversity of isolates with PCT, the duration between the first dose administrations until all parasites were cleared from blood circulation within $24 \mathrm{hr}$, and isolates with PCT of more than $24 \mathrm{hr}$.

For isolates that were fully genotyped at all loci, analysis of multilocus linkage disequilibrium (LD) (non-random associations of alleles from different loci) was evaluated by determining the standardized index of association $\left(I_{A}^{S}\right)$ as a measure using the LIAN v3.5 programme [13]. The significance of the

Table 1. Primer sequences, allelic size, average number of different alleles, and expected heterozygosity of 6 microsatellite markers

\begin{tabular}{|c|c|c|c|c|}
\hline Micro-satellite markers & Primer sequences ${ }^{a}$ & $\begin{array}{l}\text { Allelic size } \\
\text { (base pair) }\end{array}$ & $\begin{array}{l}\text { Average no. } \\
\text { of different alleles }\end{array}$ & $\begin{array}{l}\text { Expected heterozy-gosity } \\
\left(H_{E}\right)\end{array}$ \\
\hline PV3.502 & $\begin{array}{l}\text { F: CCA TGG ACA ACG GGT TAG } \\
\text { R: TCC TAC TCA GGG GGA ATA CT } \\
\text { F: HEX-GTG GAC CGA TGG ACC TAT }\end{array}$ & $128-264$ & 10.5 & 0.862 \\
\hline PV3.27 & $\begin{array}{l}\text { F: AAG CTG CAC TGA ATT ATG CT } \\
\text { R: TTC CAA ATG TAT GTG CAG TC } \\
\text { F: FAM-AGC ACA AGC ATA TGC AAA A }\end{array}$ & $89-237$ & 11.8 & 0.881 \\
\hline MS1 & $\begin{array}{l}\text { F: 6-FAM-TCA ACT GTT GGA AGG GCA AT } \\
\text { R: ctgtctt TTG CTG CGT TIT TGT TTC TG }\end{array}$ & $222-255$ & 7.3 & 0.791 \\
\hline MS5 & $\begin{array}{l}\text { F: TAMRA-CGT CCT CTA TCG CGT ACA CA } \\
\text { R: ctgtctt GGA GGA CAT CAA CGG GAT T }\end{array}$ & $118-202$ & 13.3 & 0.902 \\
\hline MS6 & $\begin{array}{l}\text { F: HEX- GGT TCT TCG GTG ATC TCT GC } \\
\text { R: ctgtctt GGA GGA CAT CAA CGG GAT T }\end{array}$ & $211-268$ & 12.5 & 0.880 \\
\hline \multirow[t]{2}{*}{ MS16 } & $\begin{array}{l}\text { F: NED-TGT TGT GGT TGT TGA TGG TGA } \\
\text { R: ctgtctt GTC GGG GAG AAC AAC AAC AT }\end{array}$ & $184-497$ & 23.5 & 0.946 \\
\hline & All markers & & 13.1 & \\
\hline
\end{tabular}

aPrimer sequences of PV3.502 and PV3.27 followed [7], MS1 and MS6 [8], MS5 [9], and MS16 [10]. 
$I_{A}^{S}$ estimate was assessed with Monte Carlo simulation using 10,000 random per mutations of data. Differences of the estimated mean $H_{\mathrm{E}}$ for each population and $I_{A}^{S}$ were also calculated.

\section{Population structure and genetic differentiation}

The program STRUCTURE version 2.3.4 [14] was used to test whether individuals clustered according to geographic origin, employing a Bayesian approach to identify the number of clusters $(\mathrm{K})$ in the dataset without any prior information on the origin of the population. Structure runs were performed exploring $\mathrm{K}$ from 1 to 5 (10 iterations each), consisting of a burn-in period of 50,000 iterations followed by 100,000 Markov Chain Monte Carlo (MCMC) iterations, assuming a mixture model and correlated allele frequencies. The admixture model was used in all analysis that allows for the presence of individuals with ancestry in 2 or more of the K population. The most likely K was defined according to Evanno et al. [15] by calculating the rate of change of $\mathrm{K}(\triangle \mathrm{K})$ using STRUCTURE HARVESTER v 0.6.94 [16]. The haplotypes with $>85 \%$ ancestry were assigned to a specific cluster for later cluster differentiation analysis. The posterior probability for each number of populations or cluster $(\mathrm{K})$ is computed and then the $\mathrm{K}$ value that better explains the genetic data is an estimate of the number of circulating clusters.

Genetic differentiation between populations $\left(F_{\text {ST }}\right)$ was estimated using Wright's F statistics to confirm if there was strong genetic differentiation within subpopulation [17]. F $_{\text {ST }}$ estimates ranged from 0 (no genetic differentiation between clusters) to 1 (full differentiation).

\section{RESULTS}

Thirty-five of the 234 samples exhibited single allele per locus, indicating a single infection, while the remaining 199
(85\%) showed multiple alleles per at least 1 locus, implying multiple infections. When grouping samples according to their areas of collection, a greater proportion of mixed clone infections were found in samples from Yala (YL) and Chanthaburi (CB) Provinces (90.9\%), with 10\% more than the amount of mixed infections found in samples from Mae Hon Son (MH) and Kanchanaburi (KN) Provinces (80.4\% and 79.4\%, respectively; Table 2).

\section{Genetic diversity and differentiation among $P$. vivax populations}

Overall, high levels of diversity were observed. All 6 microsatellite markers used in this study were high polymorphic, with the $H_{\mathrm{E}}$ of each marker ranged from 0.791 to 0.946 (Table 1). The total number of distinct alleles observed per locus ranged from 7.3 for MS1 to 23.5 for MS16 with an overall mean of 13.1 alleles/microsatellite markers and a mean value of 26 alleles/study site (Tables 1,2). Multiplicity of infection (MOI) ranged from $79.4-90.9 \%$ with a mean of $85 \%$ (Table 2).

Strong genetic diversity was observed across all study sites. The expected heterozygosity $\left(H_{\mathrm{E}}\right)$ values for parasite population ranged from 0.587 to 0.903 (mean $\pm \mathrm{SE}=0.873 \pm 0.021$; Table 2). In particular, the $\mathrm{MH}$ and $\mathrm{KN}$ isolates displayed the greatest level of diversity (mean $H_{\mathrm{E}}=0.903$ and 0.885 ), whereas the moderate diversity was observed in $\mathrm{YL}$ and $\mathrm{CB}$ isolates $\left(H_{\mathrm{E}}=0.587\right.$ and 0.695$)$. Isolates from $\mathrm{MH}$ and $\mathrm{KN}$ Province were quite similar with the highest level of genetic diversity as shown by mean number of alleles $\left(\mathrm{N}_{\mathrm{A}} ; 15.833\right.$ and 18.333), $H_{\mathrm{E}}(0.903$ and 0.885$)$, and \%MOI (80.4 and 79.4) (Table 2).

Most parasite isolates were highly polymorphic and showed unique haplotypes. Within all populations, 215 different haplotypes were detected, of which 8 haplotypes appeared in more than once in the population, i.e., 3 in population from YL and 5 in population from CB. Shared haplotypes were seen between 3 pairs of isolates from YL isolates and 2 pairs from

Table 2. Genetic diversity of 6 microsatellite markers of $P$. vivax according to sites of data collection

\begin{tabular}{|c|c|c|c|c|c|c|c|}
\hline Location & $n$ & $\mathrm{MOI}(\%)$ & $\begin{array}{c}\text { No. of } \\
\text { haplotypes }\end{array}$ & $\mathrm{N}_{\mathrm{A}}$ & $H_{E}$ & $I_{A}^{S}$ & $P$-value \\
\hline Mae Hong Son & 56 & 80.4 & 56 & 15.833 & $0.903 \pm 0.023$ & 0.023 & 0.00090 \\
\hline Kanchanaburi & 68 & 79.4 & 68 & 18.333 & $0.885 \pm 0.028$ & 0.013 & 0.00700 \\
\hline Yala & 55 & 90.9 & 53 & 9.667 & $0.587 \pm 0.073$ & 0.152 & 0.00001 \\
\hline Chanthaburi & 55 & 90.9 & 51 & 8.667 & $0.695 \pm 0.047$ & 0.309 & 0.00001 \\
\hline Mean population Level & 234 & 85.0 & & 26.000 & $0.873 \pm 0.021$ & 0.133 & 0.00001 \\
\hline
\end{tabular}

n, number of isolates; MOI, multiplicity of infection; $N_{A}$, mean number of alleles; $H_{E}$, expected heterozygosity; $I_{A}^{S}$, linkage disequilibrium (is considered significant if $P$-value is $\leq 0.05)$. 
CB isolates. In addition, 3 haplotypes, 2 shared by 7 isolates, and 1 shared by 3 isolates were present in $\mathrm{CB}$ isolates.

\section{Linkage disequilibrium}

The analyzed $P$. vivax populations showed a significant linkage disequilibrium $\left(I_{A}^{S}=0.133, P<0.001\right.$; Table 2$)$. $I_{A}^{S}$ was also calculated separately for the isolates considering their geographic location, demonstrating significant linkage disequilibrium for all locations $\left(I_{A}^{S}=0.023,0.013,0.152\right.$, and $0.309, P<$ 0.001; Table 2).

\section{Population structure and genetic differentiation}

According to the 6 microsatellite data set, cluster analysis showed that the highest Delta $K$ values $(\Delta K)$ was observed at $\mathrm{K}=3$ (Fig. 2) suggesting that the P. vivax population from 4 high malaria endemic areas of Thailand could be divided into
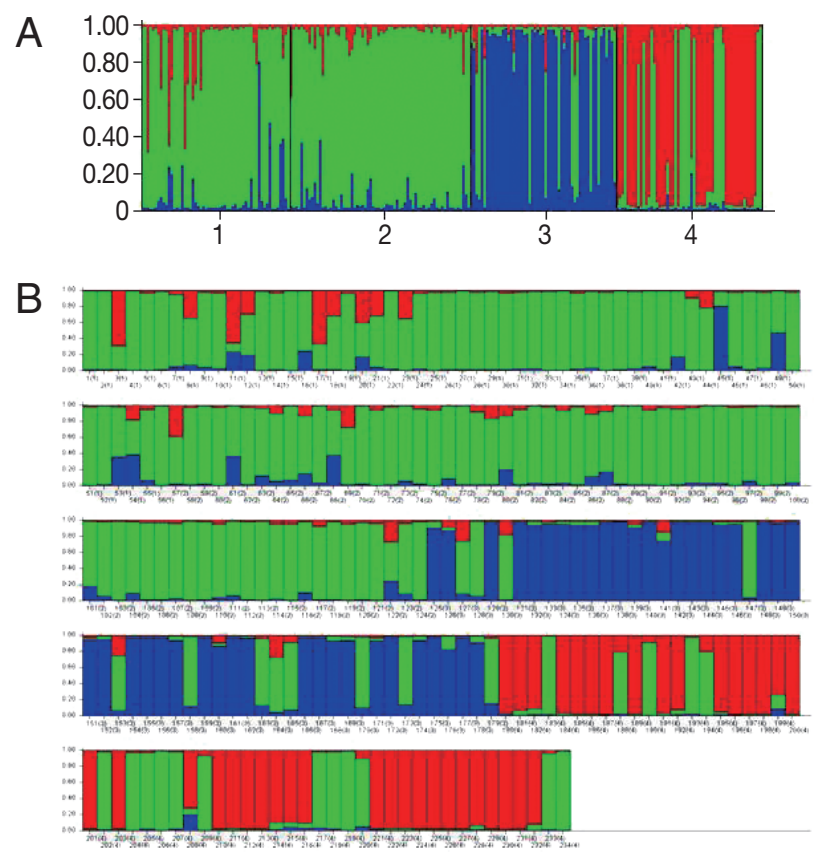

Fig. 2. Genetic clustering analysis. (A) Population structure of Plasmodium vivax plotted in a single line (cluster A, red; cluster B, green; cluster $\mathrm{C}$, blue) inferred from microsatellite typing of 234 isolates at $K=3$ using the STRUCTURE program. Isolates are numbered as 1 from Mae Hong Son $(\mathrm{MH}), 2$ from Kanchanaburi (KN), 3 from Yala (YL), and 4 from Chanthaburi (CB) Provinces. (B) Population structure of $P$. vivax plotted in multiple lines according to geographic origin. Isolates labeled with number and location in bracket $(1=\mathrm{MH}, 2=\mathrm{KN}, 3=\mathrm{YL}$, and $4=\mathrm{CB})$. In the bar plot, each isolate is represented by a single vertical line broken into $\mathrm{K}$ colored segments, with lengths proportional to each of the $\mathrm{K}$ inferred clusters.
3 clusters ( $\mathrm{A}, \mathrm{B}$, and $\mathrm{C}$ ). Most parasites were admixed as shown by bars partitioned into $\mathrm{K}$ colored segments (Fig. 2B). Isolates from $\mathrm{CB}$ were clustered into cluster $\mathrm{A}, \mathrm{MH}$ and $\mathrm{KN}$ in cluster $\mathrm{B}$, and $\mathrm{YL}$ in cluster $\mathrm{C}$. MH had the highest proportion of admixed population (28.6\%), followed by KN (19.1\%), YL (16.4\%), while CB had the lowest admixed population (9.1\%).

$F_{\text {ST }}$ pairwise analysis showed high and significant genetic differentiation ( $F_{\text {ST }}$ value from 0.204 to 0.471 ) between the clusters. All values were significantly different from $0(P<0.05)$. The highest differentiation was between $\mathrm{CB}$ isolates (cluster A) and YL isolates (cluster $\mathrm{C})\left(F_{\mathrm{ST}}=0.471\right.$, Table 3$)$.

\section{Genetic diversity comparison according to parasite clearance time}

Chloroquine ( $25 \mathrm{mg} / \mathrm{kg}$ divided for 3 days) plus primaquine (15 mg daily for 14 days) is the first line treatment drugs for uncomplicated vivax malaria in Thailand. Two hundred and seven (207) out of 234 total samples had PCT data obtained from the previous study [2]. Of these, 69 samples had PCT within $24 \mathrm{hr}$ and 138 samples had PCT of more than $24 \mathrm{hr}$. Isolates from patients with PCT $>24 \mathrm{hr}$ had higher $\mathrm{N}_{\mathrm{A}}$ and $H_{\mathrm{E}}$ compared to those with PCT within $24 \mathrm{hr}$, while MOI was similar between these groups (Table 4). In addition, 81.5\%, 75.6\%, and $98.1 \%$ of $\mathrm{MH}, \mathrm{KN}$, and $\mathrm{CB}$ isolates had PCT of more than $24 \mathrm{hr}$ implying of lower parasite response to the treatment drugs. In contrast, YL isolates had higher response to the drug, and only 13\% of YL isolates had PCT of more than $24 \mathrm{hr}$.

Table 3. Microsatellite-based genetic differentiation $\left(F_{\mathrm{st}}\right)^{\mathrm{a}}$ between $P$. vivax population across study sites $(P$-value $<0.05)$

\begin{tabular}{lccc}
\hline Group & Chanthaburi isolates & $\begin{array}{c}\text { Mae Hong Son and } \\
\text { Kanchanaburi isolates }\end{array}$ & Yala isolates \\
\hline A & - & \\
B & 0.204 & - & - \\
C & 0.471 & 0.209 & - \\
\hline
\end{tabular}

${ }^{\mathrm{a}} \mathrm{F}_{\text {ST: }}$ All values resulting from the pairwise comparison of each study site are significant $(P<0.05)$.

Table 4. Genetic diversity within populations of $P$. vivax obtained from patients with different parasite clearance time (PCT)

\begin{tabular}{lccc}
\hline Populations & $\mathrm{N}_{\mathrm{A}}$ & $H_{\mathrm{E}}$ & MOI (\%) \\
\hline PCT within 24 hr & 14.833 & 0.740 & 89.9 \\
PCT > 24 hr & 20.167 & 0.869 & 90.6 \\
Mean population level & 17.500 & 0.805 & 90.3 \\
\hline
\end{tabular}

$\mathrm{N}_{\mathrm{A}}$, mean no. of alleles; $H_{\mathrm{E}}$, expected heterozygosity; MOI, multiplicity of infection. 


\section{DISCUSSION}

We analyzed the genetic diversity and population structure of 234 P. vivax pre-treatment clinical isolates collected in 4 high malaria transmission areas of Thailand. We observed high levels of heterozygosity in P. vivax isolates from all 4-study sites and a high proportion of polyclonal infections $\left(H_{\mathrm{E}}=0.881\right.$ and $\left.\mathrm{MOI}=85 \%\right)$. The genetic differentiation $\left(F_{\mathrm{ST}}\right)$ was high indicating geographical boundaries between clusters. In concordance with the $F_{S T}$ values, the STRUCTURE analysis detected the population structure of $P$. vivax according to their geographic location (Western, Eastern, and Southern regions, $\mathrm{K}=3$ ). These results implied that $P$. vivax isolates from different origin in Thailand had different genetic structure and could be differentiate parasites from Western (MH and $\mathrm{KN}$ isolates), Southern (YL isolates), and Eastern (CB isolates) parts of Thailand. A minority of cluster A and cluster B isolates found in YL (cluster C) supports a high degree of differentiation between isolates from $\mathrm{YL}$ and the other 3 provinces. Less genetic differentiation between isolates from $\mathrm{MH}$ and $\mathrm{KN}$ can be explained by geographic proximity and socioeconomic between the inhabitants of the 2 provinces. Both provinces locate on the western part of Thailand bordered to Myanmar.

The present study clearly demonstrated that population structure of $P$. vivax isolates from YL and CB were highly different and the genetic diversity of YL isolates was lower than the other 3 Provinces. YL is geographically more isolated than $\mathrm{MH}, \mathrm{CB}$, and $\mathrm{KN}$; they are separated by 2,008, 1,329, and $1,098 \mathrm{~km}$, respectively. This is concordance to the epidemiology of malaria transmission in Yala Province. YL locates in the southern part of Thailand bordered to Malaysia while CB locates in the eastern part bordered to Cambodia. Occupation, climate, and culture of people in YL are different from people in $\mathrm{MH}, \mathrm{KN}$, and $\mathrm{CB}$. Today, most southern Muslims work in their own rubber plantations or are hired as rubber tappers if they do not have their own land. The way of life of Muslims in the southern border province is different from those of other groups in the country. Malaria patients in YL mostly were indigenous cases infected in rubber plantation areas of the Province. Migration of people is a probably effective way of malaria transmission and for gene exchanges between malaria populations. Migration to and out of YL is limited. In addition, the outbreak of violence of Thailand's southern province of Yala and Pattani Provinces since the year 2004 prevents people movement from the other provinces to YL. These factors large- ly hindered gene flow of malaria parasite population between YL isolates and $\mathrm{CB}, \mathrm{MH}$, and $\mathrm{KN}$ isolates. Therefore, populations of $P$. vivax in $\mathrm{YL}$ appear to act as independent evolutionary units because of limited gene flow.

Genetic structure of $P$. vivax isolates from $\mathrm{MH}$ and $\mathrm{KN}$ were similar but very different from YL and CB. The similarity of genetic structure of isolates from $\mathrm{MH}$ and $\mathrm{KN}$ may result from the location of the 2 provinces and the same mountainous areas. $\mathrm{MH}$ and $\mathrm{KN}$ locate on the western border with Myanmar. Anopheles vectors are prominent in the mountainous-forested areas leading to high malaria transmission along the western border areas. People living in the hilly pocket villages situated in the forests or forest fringe areas on or near the border of Thai-Myanmar are at risk of malaria infection. The border crossings of people in each site of land borders are also epidemiologically linked with transmission dynamics of both $P$. falciparum and P. vivax [18].

Chloroquine plus primaquine, the first line treatment of uncomplicated vivax malaria in Thailand is still effective; the cure rate is more than 95\% [2]. However, PCT of $P$. vivax isolates from $\mathrm{CB}$ was longer than isolates from $\mathrm{YL}$ [2]. $\mathrm{CB}$ is a high transmission area situated close to the Thai-Cambodia border where it is considered an epicenter of anti-malarial drug resistance. The resistance situation remains critical in areas along the Thai-Cambodia border, although the incidence of malaria infection has been declining drastically [19]. According to the continuous anti-malarial drug surveillance of the Thailand $\mathrm{Na}$ tional Malaria Control Programme, malaria parasite from $\mathrm{CB}$, especially $P$. falciparum, highly resists to almost all anti-malarial drugs availability nowadays whereas parasite from $\mathrm{YL}$ is higher sensitive [3]. Compared to isolates from the western part ( $\mathrm{MH}$ and $\mathrm{KN}$ isolates), $\mathrm{CB}$ isolates had less genetic diversity. It may result from the current situation of low malaria transmission in the eastern part of Thailand.

The genetic characteristics classified by PCT were different. The group with PCT of more than 24 hr had higher diversity. The group with PCT within $24 \mathrm{hr}$ comprised most P. vivax isolates from YL while those with PCT of more than $24 \mathrm{hr}$ comprised most isolates from CB. From the previous study [2], mean PCTs were calculated and compared using Long Rank (Mantel-Cox) in the Kaplan-Meier analysis. PCT of patients from $\mathrm{CB}$ was significantly longer than those from $\mathrm{MH}, \mathrm{KN}$, and YL [2]. The mean PCT was 3.7 days, compared to 2 days of $\mathrm{MH}, 1.6$ days of $\mathrm{KN}$, and 1.1 days of YL isolates. This finding confirmed the genetic difference of $P$. vivax isolates from 
$\mathrm{YL}$ and $\mathrm{CB}$. The difference of genetic characteristics is likely to relate with disease severity.

A better understanding of $P$. vivax genetic diversity and genetic structure of parasite population in this study are beneficial to malaria control programme as it is a useful tool to track the source of infections. In addition, it is important for the evaluation and improvement of current efforts for malaria control and elimination.

\section{ACKNOWLEDGMENTS}

We thank National Research Board of Thailand for funding support. This study could not be successful if we did not receive help from Mr. Theerasak Hoonchaiyapoom, a medical scientist of the Bureau of Vector Borne Disease, Department of Disease Control, Ministry of Public Health, and Mr. Ekkachai Kamfan and Ms. Wirachada, B.Sc. students of the Department of Medical Technology, Faculty of Science and Technology, Bansomdejchaopraya Rajabhat University, Thailand for their works in the molecular laboratories. We thanked AFRIMS for allowance us to use equipments and supplies for molecular laboratory.

\section{CONFLICT OF INTEREST}

We have no conflict of interest related to this study.

\section{REFERENCES}

1. Bureau of Vector Borne Disease. Malaria Situation. In Chinanonwes N ed., Annual Report, 2015. Bangkok, Thailand. Aksorn Graphic and Design. 2015, pp 14-18.

2. Congpuong K, Satimai W, Sujariyakul A, Intanakom S, Harnpitakpong W, Pranuth Y. Cholpol S, Bualombai P. In vivo sensitivity monitoring of chloroquine for the treatment of uncomplicated vivax malaria in four bordered provinces of Thailand during 2009-2010. J Vector Borne Dis 2011; 48: 190-196.

3. Alam MT, Vinayak S, Congpuong K, Wongsrichanalai C, Satimai W, Slutsker L, Escalante AA, Barnwell JW, Udhayakumar V. Tracking origins and spread of sulfadoxine-resistant Plasmodium falciparum dhps alleles in Thailand. Antimicrob Agents Chemother 2011; 55: 155-164.

4. Pumpaibool T, Arnathau C, Durand P, Kanchanakhan N, Siripoon N, Suegorn A, Sitthi-Amorn C, Renaud F, Harnyuttanakom P. Genetic diversity and population structure of Plasmodium falciparum in Thailand, a low transmission country. Malar J 2009; 14; 8: 155.

5. Hong NV, Delgado-Ratto C, Thanh PV, Van den Eede P, Guetens
P, Binh NT, Phuc BQ, Duong TT, Van Geertruyden JP, D'Alessandro U, Erhart A, Rosanas-Urgell A. Population genetics of Plasmodium vivax in four rural communities in Central Vietnam. PLoS Negl Trop Dis 2016; 10: e0004434.

6. Iwagami M, Fukumoto M, Hwang SY, Kim SH, Kho WG, Kano S. Population structure and transmission dynamics of Plasmodium vivax in the Republic of Korea based on microsatellite DNA analysis. PLoS Negl Trop Dis 2012; 6: e1592.

7. Imwong M, Nair S, Pukrittayakamee S, Sudimack D, Williams JT, Mayxay M, Newton PN, Kim JR, Nandy A, Osorio L, Carlton JM, White NJ, Day NP, Anderson TJ. Contrasting genetic structure in Plasmodium vivax populations from Asia and South America. Int J Parasitol 2007; 37: 1013-1022.

8. Orjuela-Sánchez P, Sá JM, Brandi MC, Rodrigues PT, Bastos MS, Amaratunga C, Duong S, Fairhurst RM, Ferreira MU. Higher microsatellite diversity in Plasmodium vivax than in sympatric Plasmodium falciparum populations in Pursat, Western Cambodia. Exp Parasitol 2013; 134: 318-326.

9. Gunawardena S, Karunaweera ND, Ferreira MU, Phone-Kyaw M, Pollack RJ, Alifrangis M, Rajakaruna RS, Konradsen F, Amerasinghe PH, Schoussboe ML, Galappaththy GN, Abeyasinghe RR, Hartl DL, Wirth DF. Geographic structure of Plasmodium vivax: microsatellite analysis of parasite populations from Sri Lanka, Myanmar, and Ethiopia. Am J Trop Med Hyg 2010; 82: 235-242.

10. Koepfli C, Timinao L, Antao T, Barry AE, Siba P, Mueller I, Felger I. A large Plasmodium vivax reservoir and little population structure in the south Pacific. PLoS One 2013; 8: e66041.

11. Sutton PL. A call to arms: on refining Plasmodium vivax microsatellite marker panels for comparing global diversity. Malar J 2013; 12: 447.

12. Peakall R, Smouse PE. GenAlEx 6.5: genetic analysis in Excel. Population genetic software for teaching and research-an update. Bioinformatics 2012; 28: 2537-2539.

13. Haubold B and Hudson RR. LIAN 3.0: LIAN 3.0: detecting linkage disequilibrium in multilocus data. Bioinformatics 2000; 16: 847-848.

14. Pritchard Lab, Standford University. Download Structure 2.3.4 [Internet]. 2012 Jul [cited 2017 Apr 23]. Available from: http:// web.stanford.edu/group/pritchardlab/Structure_Software/release_versios/v2.3.4/html/structure.html.

15. Evanno G, Regnaut S, Goudet J. Detecting the number of clusters of individuals using the software STRUCTURE: a simulation study. Mol Ecol 2005; 14: 2611-2620.

16. Earl DA, vonHoldt BM. STRUCTURE HARVESTER: a website and program for visualising STRUCTURE output and implementing the Evanno method. Conserv Genet Resour 2012; 359361.

17. Chenet SM, Schneider KA, Villgeas L, Escalante AA. Local population structure of Plasmodium: impact on malaria control and elimination. Malar J 2012; 11: 412.

18. Bhumiratana A, Intarapuk A, Sorosjinda-Nunthawarasilp P, Maneekan P, Koyadun S. Border malaria associated with multidrug resistance on Thailand-Myanmar and Thailand-Cambodia bor- 
ders: transmission dynamic, vulnerability, and surveillance. Biomed Res Int 2013; 2013: 363417.

19. Satimai W, Sudathip P, Vijaykadga S, Khamsiriwatchara A, Sawang S, Potithavoranan T, Sangvichean A, Delacollette C, Singha- sivanon P, Kaewkungwal J, Lawpoolsri S. Artemisinin resistance containment project in Thailand. II: responses to mefloquineartesunate combination therapy among falciparum malaria patients in provinces bordering Cambodia. Malar J 2012; 11: 300. 